\title{
Lung resistance-related protein as a predictor of clinical outcome in advanced testicular germ-cell tumours
}

\author{
AJ Zurita ${ }^{1,4}$, JE Diestra', E Condom², X García del Muro', GL Scheffer ${ }^{3}$, RJ Scheper', J Pérez', JR Germà-Lluch' \\ and MA Izquierdo*,'
}

'Department of Medical Oncology and Laboratory of Translational Research, Institut Català d'Oncologia, Av Gran Via Km 2.7, 08907 Barcelona, Spain; ${ }^{2}$ Department of Pathology, Ciutat Sanitària i Universitària de Bellvitge, Feixa Llarga s/n, 08907 Barcelona, Spain; ${ }^{3}$ Department of Pathology, Free

University Hospital, De Boelelaan 1 1 17, 1081 HV Amsterdam, the Netherlands

\begin{abstract}
This study was undertaken to investigate the expression and predictive value for outcome of multidrug resistance-associated (MDR) proteins P-glycoprotein (PgP), MRPI, BCRP, and LRP, in advanced testicular germ-cell tumours (TGCT). Paraffin-embedded sections from 56 previously untreated patients with metastatic TGCT were immunostained for Pgp, MRPI, BCRP, and LRP. All patients received platinum-based chemotherapy after orchidectomy. Immunostaining was related to clinicopathological parameters, response to chemotherapy, and outcome. Strong and intermediate expressions of the different MDR-related proteins were: 27 and $41 \%$ (Pgp), 54 and 37\% (MRPI), 86 and 7\% (BCRP), and 14 and 29\% (LRP). P-glycoprotein and MRPI associated, respectively, to low AFP $(P=0.026)$ and high LDH levels $(P=0.014)$, whereas LRP expression associated with high $\beta$-hCG levels $(P=0.003)$ and stage IV tumours $(P=0.029)$. No correlation was found between Pgp, MRPI, and BCRP expression and response to chemotherapy and survival. In contrast, patients with LRP-positive tumours (strong or intermediate expression) had shorter progression-free $(P=0.0006)$ and overall survival $(P=0.0116)$ than LRP-negative patients, even after individual log-rank adjustments by statistically associated variables. Our data suggest that a positive LRP immunostaining at the time of diagnosis in metastatic TGCT is associated with an adverse clinical outcome.
\end{abstract}

British Journal of Cancer (2003) 88, 879-886. doi: I0.1 038/sj.bjc.6600803 www.bjcancer.com

(c) 2003 Cancer Research UK

Keywords: testicular germ-cell tumours; lung resistance-related protein; P-glycoprotein; multidrug resistance-associated protein I; breast cancer resistance protein; multidrug resistance

Current use of cisplatin-based chemotherapy and surgery in the first-line treatment of advanced testicular germ-cell tumours (TGCT) results in long-term disease-free status in about $80 \%$ of cases (Bosl and Motzer, 1997; Horwich et al, 1998). As a result of the high cure rate and the morbidity of treatment, clinical research has focused on optimising the management of this disease, tailoring therapies according to the risk of failure of the individual patient (Bosl and Motzer, 1997; Sonneveld et al, 2001). Factors associated with a poor-outcome have been analysed in several large studies, and include the extent of metastatic disease and serum levels of the $\beta$-subunit of human chorionic gonadotropin ( $\beta$-hCG), $\alpha$-fetoprotein (AFP) and lactate dehydrogenase (LDH) (Germà-Lluch et al, 1980; Mead et al, 1992). The most recent and

*Correspondence: Dr MA Izquierdo, Department of Medical Oncology, Institut Català d'Oncologia, Av. Gran Via, Km 2.7, Hospitalet de Llobregat, 08907 Barcelona, Spain;

E-mail: maizquierdo.delso@csub.scs.es

${ }^{4}$ Current address: Department of Genito-Urinary Medical Oncology, The University of Texas MD Anderson Cancer Center, I5I5 Holcombe Boulevard, Houston, TX 77030, USA

Received 2 October 2002; revised 12 December 2002; accepted 12 December 2002 commonly employed prognostic model for disseminated disease is the International Germ Cell Consensus Classification (IGCCC), which predicts relapse at 5 years for 12,25 , and $59 \%$ patients in the good, intermediate, and poor prognosis groups, respectively (International Germ Cell Cancer Collaborative Group, 1997).

Treatment failure in this disease is closely related to inherent or developed resistance to chemotherapy (Bosl and Motzer, 1997). Patients with refractory disease, failing to respond to initial treatment, have a worse prognosis (Motzer et al, 1991). However, current knowledge of the molecular determinants of chemoresistance involved in TGCT is only marginal (Houldsworth et al, 1998; Rao et al, 1998; Kersemaekers et al, 2002).

In particular, little is known about clinical multidrug resistance (MDR) in TGCT (Van Brussel and Mickisch, 1998). Multidrug resistance consists of de novo or acquired cross-resistance to structurally and functionally unrelated drugs, some of them relevant in the treatment of TGCT such as Vinca alkaloids, epipodophyllotoxins and anthracyclines (Lehnert, 1996). Among the various molecular mechanisms associated with MDR in experimental tumour models, one of the most extensively studied involves decreased drug accumulation due to enhanced efflux by ATP-dependent transporter proteins such as P-glycoprotein (Pgp), the human multidrug resistance-associated protein 1 (MRP1), and the recently described breast cancer resistance protein (BCRP). 
880

P-glycoprotein overexpression is associated with resistance to natural product drugs, including anthracyclines, etoposide, vincristine and vinblastine, and paclitaxel (Germann, 1996). Multidrug resistance-associated protein 1 is overexpressed in many non-Pgp-mediated MDR cell lines, conferring in vitro resistance, among others, to etoposide, vincristine, vinblastine, and to methotrexate after short-term exposure (Borst et al, 2000). Breast cancer resistance protein is a newly described transporter, isolated from mitoxantrone-selected MDR cell lines not expressing Pgp or MRP (Allikmets et al, 1998; Doyle et al, 1998). Breast cancer resistance protein is associated with cross-resistance to dauno- and doxorubicin, mitoxantrone, and camptothecins (Maliepaard et al, 1999).

Another protein related to an MDR-phenotype is the lung resistance-related protein (LRP) (Scheper et al, 1993). Lung resistance-related protein has been identified as the human major vault protein (MVP), the principal constituent of the complex ribonucleoprotein particles known as vaults (Scheffer et al, 1995). Of interest in TGCT, LRP/vaults have been associated with in vitro resistance to drugs such as etoposide, doxorubicin, vincristine, and paclitaxel, but also to nonclassical MDR drugs such as cisplatin and carboplatin (Izquierdo et al, 1996a; Kitazono et al, 1999). Although the function of vaults in both normal and cancer cells is not fully elucidated, they are thought to be involved in intracellular redistribution of drugs, reducing exposure of nuclear targets from cytotoxic agents (Chugani et al, 1993; Kitazono et al, 1999).

We undertook the present study to assess the immunohistochemical expression of the MDR-related proteins Pgp, MRP1, BCRP, and LRP in advanced TGCT, and to determine whether such expression is related to response to first-line chemotherapy and survival.

\section{PATIENTS AND METHODS}

The expression of MDR-related proteins Pgp, MRP1, BCRP, and LRP was studied in paraffin-embedded samples from patients with advanced TGCT. This expression was retrospectively correlated with clinical and pathological characteristics of the patients, response to chemotherapy, and outcome.

\section{Sample selection}

Between March 1990 and February 2001, 65 patients with primary advanced TGCT were treated in our institution. We studied banked samples from 56 specimens, corresponding to previously untreated patients undergoing orchidectomy for diagnostic evaluation and treatment. Samples were obtained from the Department of Pathology at the Ciutat Sanitària i Universitària de Bellvitge, Barcelona, Spain. Eligible patients were those with advanced disease (stage I excluded) undergoing induction chemotherapy, and with available material. The histological diagnosis was based on conventional morphologic examination of paraffin sections, following World Health Organization criteria (Mostofi and Sesterhenn, 1998).

\section{Treatment, evaluation of response, and survival}

All patients were primarily treated with inguinal orchidectomy and postoperative cisplatin-based induction chemotherapy. Immediately after conventional induction chemotherapy, seven poor-risk patients (IGCCC) received high-dose chemotherapy as consolidation treatment. Complete responders to chemotherapy (CR) were patients with normalisation of serum tumour markers and no clinical or radiological evidence of residual masses, or absence of viable cancer cells such as seminoma, embryonal carcinoma (EC), immature teratoma, yolk sac tumour (YS), choriocarcinoma
(CC), and syncytiotrophoblastic cells in completely resected residual masses (mature teratoma (MT) was not considered malignant component). Complete responders to chemotherapy plus surgery (CR-S) were those with viable malignant cells in completely resected residual masses. Incomplete responders (IR) were patients with persisting elevation of tumour markers, incomplete surgical resection of residual disease, or disease progression while receiving chemotherapy or within 1 month after the completion of chemotherapy. Events in the progression-free survival (PFS) analysis were: incomplete response, and relapse (rising tumour markers and/or an increase in tumour volume, unless caused by completely resectable MT). Patients in progression were managed with a variety of second-line chemotherapy regimens and surgery if appropriate. Only deaths related to TGCT progression were considered as events for overall survival (OS) analysis.

\section{Monoclonal antibodies}

The IgG1 murine monoclonal antibody (MAb) JSB-1 was used for Pgp detection in a concentration of $50 \mu \mathrm{g} \mathrm{ml}^{-1}$ in phosphatebuffered saline (PBS) plus 1\% bovine serum albumin (BSA, Sigma, St Louis, MO, USA). For MRP1, the IgG2a MAb MRPm5 was used in a concentration of $5 \mu \mathrm{g} \mathrm{m}^{-1}$ in $1 \% \mathrm{PBS} / \mathrm{BSA}$. For BCRP, the newly described IgG2a MAb BXP-21 was used in a concentration of $25 \mu \mathrm{g} \mathrm{ml}^{-1}$ in $1 \% \mathrm{PBS} / \mathrm{BSA}$. JSB-1, MRPm5, and BXP-21 were obtained from the Department of Pathology, Free University Hospital, Amsterdam, the Netherlands (Scheper et al, 1988; Flens et al, 1994; Maliepaard et al, 2001). None of these three MAbs cross react with the other MDR proteins (Maliepaard et al, 2001). Finally, the IgG1 murine MAb LRP (Transduction Labs, Los Angeles, CA, USA) was used for detection of LRP in a concentration of $2.5 \mu \mathrm{g} \mathrm{ml}^{-1}$ in $1 \% \mathrm{PBS} / \mathrm{BSA}$.

\section{Immunohistochemistry}

Immunohistochemistry was performed on $4 \mu \mathrm{m}$ formalin-fixed, paraffin-embedded sections mounted on poly-L-lysin-coated glass microslides, and dried at $37^{\circ} \mathrm{C} \mathrm{O} / \mathrm{N}$. The immunoperoxidase reaction conditions used for each MAb were selected on the basis of previous optimisation of the immunohistochemical protocols. After conventional deparaffination and rehydration, endogenous peroxidase activity was quenched by incubation in $3 \% \mathrm{H}_{2} \mathrm{O}_{2}$ $(10 \mathrm{~min})$ at room temperature. Pretreatment in a pressure cooker (20 min) with either citrate buffer $(10 \mathrm{~mm}$ citric acid pH 6.0 in distilled water) for MRPm5, LRP, and BXP-21, or EDTA (1 mM) for JSB-1 was performed to unmask epitopes. Next, samples were incubated (30 min) in normal rabbit serum (1:50 in 1\% PBS/BSA), and then with the optimally diluted specific antibody $(60 \mathrm{~min})$ at room temperature in a humidified chamber. The MAb BXP-21 was detected by the Dako EnVision ${ }^{\mathrm{TM}}+$ System-horseradish peroxidase (Dako Corp., Glostrup, Denmark) for $30 \mathrm{~min}$ (Diestra et al, 2002). A rabbit anti-mouse biotin-conjugated (1:150 for $30 \mathrm{~min}$, Zymed Labs, San Francisco, CA, USA) followed by a streptavidin horseradish peroxidase (1:500 for $1 \mathrm{~h}$, Zymed) method was used for MAbs MRPm5 and LRP. JSB-1 was developed by a twice-each alternating incubation with a rabbit anti-mouse biotin-conjugated method (1:500 for $30 \mathrm{~min}$, Dako) followed by a streptavidinbiotin complex $(1: 200$ for $1 \mathrm{~h}$, Dako). Staining with an irrelevant IgG or an isotype-specific antibody was routinely performed as a negative control procedure in the normal tissues and in all the clinical samples. Bound peroxidase was developed with $3,3^{\prime}$ diaminobenzidine (Sigma).

As positive control tissues for the immunohistochemical assays, liver was used for JSB-1 (Van der Valk et al, 1990), colon for MRPm5 (Flens et al, 1996) and LRP (Izquierdo et al, 1996b), and placenta for BXP-21 (Maliepaard et al, 2001). All slides were 
examined and scored by two independent observers (EC and AZ) blinded to the clinical data. Tumour cells were identified on morphological criteria. The MDR proteins were studied in adjacent slides from the most representative paraffin block available for each specimen. Only viable malignant germ cells (excluding MT elements) were considered for evaluation. By prior agreement, in accordance with previous literature, sections were evaluated in a semi quantitative way taking into account the percentage and intensity of staining of tumour cells (Baldini et al, 1995; Izquierdo et al, 1995; Arts et al, 1999; Eid et al, 2000). Three staining categories were established: negative (no staining), intermediate (positive staining in $\leqslant 10 \%$ of tumour cells or weak and diffuse positive staining), and strong (moderate/strong staining in $>10 \%$ of tumour cells). A priori, it was planned that the intermediate category needed to be grouped with either the negative or the strong category for statistical correlations (see below). The reasons for this were: (1) to ascertain whether the intermediate category provided more predictive information for each protein when grouped with any of the other two categories; (2) to perform meaningful statistical analysis with only two groups because of the limited number of patients; (3) a clinical relevant cut-off level of expression of MDR proteins is not well defined yet and it may be different for each protein and each tumour type. Intensity and pattern of staining on the different histological subtypes in each sample were recorded separately.

\section{Statistical analysis}

Clinicopathological characteristics were determined previous to chemotherapy. These characteristics and response rates to induction chemotherapy were retrospectively assessed for their relation with Pgp, MRP1, BCRP, and LRP expression, using $\chi^{2}$ or the Fisher's exact two-tailed test as appropriate. For survival analysis, follow-up started the date of the first cycle of induction chemotherapy. Univariate survival analysis curves were generated using the Kaplan - Meier method and compared using the log- rank test (Kaplan and Meier, 1958; Mantel, 1966). A stratified Mantel - Haenszel test was performed to compare survival curves in order to adjust for the potential confounding effect of statistically associated variables upon differences between groups. Hypotheses were evaluated at a two-sided significance level of 0.05. The SPSS package (SPSS Inc, Chicago, IL, USA) was used for calculations.

\section{RESULTS}

\section{Clinical and pathological characteristics, response to chemotherapy, and outcome}

The median age at initial orchidectomy was 24 years (range, 16-56 years). No patient had a previous history of cancer, except for one (2\%) having a contralateral and successfully treated TGCT more than 9 years before. The characteristics of the 56 patients included in the study are summarised in Table 1 (left column). The 52 nonseminomatous TGCT included: 41 mixed tumours, seven EC, three YS, and one CC. Thirty-five (62\%) were good-risk patients, $11(20 \%)$ intermediate-risk, and $10(18 \%)$ poor-risk, according to the IGCCC criteria (International Germ Cell Cancer Collaborative Group, 1997). Chemotherapy regimens used (Germà-Lluch et al, 1999) are listed in Table 2. Median number of cycles was 4 (range, 2-8). One patient (2\%) was excluded from the analysis of response to chemotherapy because of a nonrelated-to-cancer death during treatment. Therefore, 55 patients were evaluable for tumour response to induction chemotherapy. Fifty-one CR (93\%), three CR-S (5\%), and one IR (2\%) to first-line chemotherapy were accounted. Among those achieving a CR, 16 underwent surgery of residual masses: six showed either necrosis or fibrosis and $10 \mathrm{MT}$ only. One of the CR-S patients actually progressed to first-line chemotherapy but underwent complete salvage surgery and continues relapse-free with more than 4 years of follow-up.

Table I Clinical and pathological characteristics according to Pgp, MRPI, BCRP, and LRP expression

\begin{tabular}{|c|c|c|c|c|c|}
\hline & No. (\%) & $\operatorname{Pgp}+(\%)^{\mathrm{a}}$ & MRP I+(\%) ${ }^{a}$ & BCRP+(\%) ${ }^{\mathbf{a}}$ & LRP+(\%) ${ }^{a}$ \\
\hline All cases & $56(100)$ & $15(27)$ & $30(54)$ & $48(86)$ & $24(43)$ \\
\hline \multicolumn{6}{|l|}{ Histology } \\
\hline Nonseminoma & $52(93)$ & $13(25)$ & $27(52)$ & $46(88.5)$ & $23(44)$ \\
\hline Seminoma & $4(7)$ & $2(50)$ & $3(75)$ & $2(50)$ & I (25) \\
\hline \multicolumn{6}{|l|}{ Stage (Royal Marsden) } \\
\hline$|M+\|-\|| \mid$ & $39(70)$ & $12(31)$ & $20(51)$ & $32(82)$ & $13(33)$ \\
\hline IV & $17(30)$ & $3(18)$ & $10(59)$ & $16(94)$ & |I $(65)^{* * * *}$ \\
\hline \multicolumn{6}{|l|}{$\begin{array}{l}\text { Pre-CT serum TM } \\
\text { AFP }\end{array}$} \\
\hline$\leqslant 1000 \mathrm{ngml}^{-1}$ & $45(80)$ & 15(33)* & $23(51)$ & $39(87)$ & $19(42)$ \\
\hline$>1000 \mathrm{ng} \mathrm{ml}^{-1}$ & $11(20)$ & $0(0)$ & $7(64)$ & $9(82)$ & $5(45.5)$ \\
\hline \multicolumn{6}{|l|}{$\beta-h C G$} \\
\hline$\leqslant 5000 \| I^{-1}$ & $47(84)$ & $13(28)$ & $24(5 \mathrm{I})$ & $40(85)$ & 16(34) \\
\hline$>5000 \mathrm{IUI}^{-1}$ & $9(16)$ & $2(22)$ & $6(67)$ & $8(89)$ & $8(89)^{* * * * *}$ \\
\hline \multicolumn{6}{|l|}{$\mathrm{LDH}$} \\
\hline$\leqslant 1.5$ upper $\mathrm{N}$ thresh & $46(82)$ & $13(28)$ & $21(46)$ & $39(85)$ & $19(4 \mid)$ \\
\hline$>1.5$ upper $\mathrm{N}$ thresh & $10(18)$ & $2(20)$ & $9(90) * *$ & $9(90)$ & $5(50)$ \\
\hline \multicolumn{6}{|l|}{ IGCCC } \\
\hline Good & $35(62.5)$ & $11(31)$ & $16(46)$ & $30(86)$ & $13(37)$ \\
\hline Intermediate or poor & $21(37.5)$ & $4(19)$ & $14(67)$ & $18(86)$ & $11(52)$ \\
\hline \multicolumn{6}{|l|}{ Vascular invasion } \\
\hline Yes & $38(68)$ & $12(32)$ & $22(58)$ & $34(89)$ & $17(45)$ \\
\hline No & $18(32)$ & $3(17)$ & $8(44)$ & $14(78)$ & $7(39)$ \\
\hline
\end{tabular}

$\mathrm{CT}=$ chemotherapy, $\mathrm{N}$ thresh=normal threshold, $\mathrm{TM}=$ tumour markers. ${ }^{\mathrm{a}} \mathrm{P} g \mathrm{p}+, \mathrm{MRPI}+$, and $\mathrm{BCRP}+$ represent immunohistochemical category strong; LRP+ represents the grouping of categories intermediate and strong (see Patients and Methods, and Results). ${ }^{*} P=0.026$ (Fisher's exact test). ${ }^{*} P=0.014$ (Fisher's exact test). **** $P=0.029$ ( $\chi^{2}$ test). ****** $P=0.003$ (Fisher's exact test). 
Table 2 First-line chemotherapy regimens

\begin{tabular}{lrr}
\hline & \multicolumn{3}{c}{ Patients (N=56) } \\
\cline { 2 - 3 } Regimens & No. & $\%$ \\
\hline BEP & & \multirow{2}{*}{ a } \\
BOMP-EPI & 37 & 66 \\
EP & 16 & 29 \\
Other platinum based & 2 & 4 \\
High dose & 1 & 1 \\
& 7 & 13 \\
\hline
\end{tabular}

$\mathrm{BEP}=$ etoposide, cisplatin, bleomycin, EP=etoposide, cisplatin, BOMP-EPI=bleomycin, vincristine, methotrexate, cisplatin/etoposide, ifosfamide, cisplatin. Includes one patient nonassessable for response. ${ }^{b}$ Immediately after conventional induction chemotherapy, seven poor-risk patients (IGCCC) received high-dose chemotherapy as consolidation treatment.

The median follow-up was 49.5 months (range 2-111 months). Seven patients (12.5\%) progressed to first-line treatment, including 1 IR and 6 relapses. Four patients (7\%) died of TGCT and two (4\%) of non-TGCT-related reasons (second carcinoma and intracranial haemorrhage).

\section{Pgp, MRP1, BCRP, and LRP expression in TGCT at diagnosis}

The results of immunohistochemistry are summarised in Table 3. Fifteen $(27 \%)$ and $23(41 \%)$ of the 56 specimens showed strong and intermediate expression of Pgp, respectively. The staining pattern was diffuse and homogeneous, cytoplasmic and occasionally membranous. Thirty (54\%) and $21(37 \%)$ of the 56 cases displayed strong and intermediate expression of MRP1, respectively. Immunostaining was rather heterogeneous. MRP1 was detected at the cytoplasm, although nuclear and scarce membranous expressions were also found. For both Pgp and MRP1, the intermediate category was composed mainly of samples with a weak expression in over $10 \%$ of tumour cells ( 20 out of 23 and 17 out of 21 , respectively). Forty-eight (86\%) and four (7\%) of the 56 cases displayed, respectively, strong and intermediate expression of BCRP, with a mixed staining pattern, membranous (particularly among EC and YS elements) and cytoplasmic (in syncytiotrophoblasts). BCRP staining intensity was mostly strong and rather homogeneous as shown in Figure 1A, except for YS elements (usually positive in areas with epithelial differentiation and negative where mesenchymal). Eight (14\%) and $16(29 \%)$ of the 56 cases displayed, respectively, strong and intermediate expression of LRP, with a typical granular cytoplasmic pattern as shown in Figure 1B (Izquierdo et al, 1996b). Intensity was mostly strong and heterogeneous, with the exception of syncytiotrophoblastic areas, which showed homogeneous staining. Remarkably, 15 of 16 samples in the intermediate category had less than $10 \%$ intense positive cells. In eight of these 15, one histological subtype (six CC and two immature teratomas) with a minor overall representation $(\leqslant 10 \%)$ was found universally positive. No staining was observed among negative controls for all four MAbs. No correlation was found between the expressions of the different proteins (data not shown).

\section{MDR status and established prognostic factors}

For the reasons described before (see Patients and Methods), the intermediate immunohistochemical category was grouped either with the negative or the strong category for statistical correlations with other prognostic factors and analysis of outcome. Table 1 summarises these correlations. Tumours with strong expression of Pgp were more frequently observed in
Table 3 Pgp, MRPI, BCRP, and LRP expressions in testicular germ-cell tumours at diagnosis

\begin{tabular}{lccc}
\hline Category & Strong $^{\mathbf{a}}$ & Intermediate & Negative $^{\mathbf{a}}$ \\
\hline $\mathrm{PgP}$ & $15(27 \%)$ & $23(41 \%)$ & $18(32 \%)$ \\
$\mathrm{MRPI}$ & $30(54 \%)$ & $21(37 \%)$ & $5(9 \%)$ \\
$\mathrm{BCRP}$ & $48(86 \%)$ & $4(7 \%)$ & $4(7 \%)$ \\
LRP & $8(14 \%)$ & $16(29 \%)$ & $32(57 \%)$ \\
\hline
\end{tabular}

aStrong: strong staining in $>10 \%$ of tumour cells; intermediate: positive staining in $\leqslant 10 \%$ of tumour cells or weak and diffuse positive staining; negative: no staining.
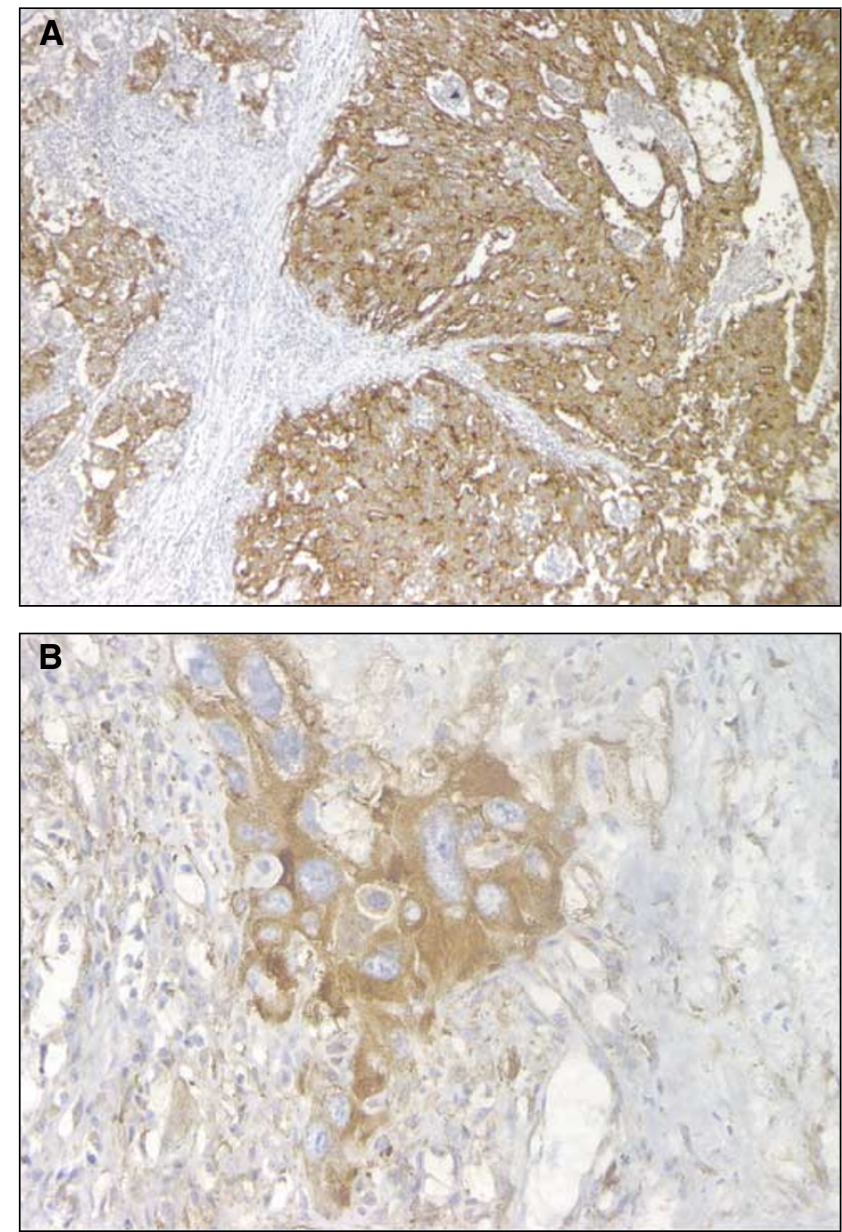

Figure I Immunohistochemical staining on paraffin-embedded specimens of testicular germ-cell tumours. $(\mathbf{A})(\times 100)$ BCRP strong positive embryonal carcinoma stained with MAb BXP-2I. Note the strong diffuse membranous and cytoplasmic staining pattern. $($ B $)(\times 200)$ LRP strong positive choriocarcinoma stained with MAb LRP. Note the strong granular cytoplasmic pattern in syncytiotrophoblastic cell.

patients with AFP levels $<1000 \mathrm{ng} \mathrm{ml}^{-1}(P=0.026)$. Tumours with strong expression of MRP1 correlated with LDH levels $>1.5$ upper normal threshold $(P=0.014)$. No association could be identified for BCRP. Tumours with strong or intermediate expression of LRP associated with $\beta$-hCG levels $>5000 \mathrm{IU} / \mathrm{l}^{-1}$ $(P=0.003)$ and stage IV $(P=0.029)$ according to the Royal Marsden Hospital (RMH) Classification (Peckham et al, 1979). 
Table 4 Expression of Pgp, MRPI, BCRP, and LRP and response to induction chemotherapy ( $n=55$ evaluable patients)

\begin{tabular}{|c|c|c|c|c|}
\hline & $n$ & CR (\%) & CR-S + IR (\%) & $P^{a}$ \\
\hline \multicolumn{5}{|l|}{$P g p^{b}$} \\
\hline+ & 14 & $12(86)$ & $2(14)$ & \multirow[t]{2}{*}{0.265} \\
\hline- & 41 & $39(95)$ & $2(5)$ & \\
\hline \multicolumn{5}{|c|}{$\left.M R P\right|^{\mathrm{b}}$} \\
\hline+ & 29 & $26(90)$ & $3(10)$ & \multirow[t]{2}{*}{0.613} \\
\hline - & 26 & $25(96)$ & I (4) & \\
\hline \multicolumn{5}{|c|}{$B C R P^{b}$} \\
\hline+ & 47 & $44(94)$ & $3(6)$ & \multirow[t]{2}{*}{0.477} \\
\hline- & 8 & $7(87.5)$ & $\mathrm{I}(\mathrm{I} 2.5)$ & \\
\hline \multicolumn{5}{|l|}{$L R P^{\mathrm{b}}$} \\
\hline+ & 23 & $21(91)$ & 2(9) & \multirow[t]{2}{*}{0.999} \\
\hline- & 32 & $30(94)$ & $2(6)$ & \\
\hline
\end{tabular}

$\mathrm{CR}=$ complete response to chemotherapy, $\mathrm{CR}-\mathrm{S}=$ complete response to chemotherapy and surgery, IR=incomplete response (see Patients and Methods). 'Fisher's exact test. 'Pgp+, MRPI+, and BCRP+ represent immunohistochemical category strong; Pgp-, MRPI-, and BCRP- represent the grouping of intermediate and negative categories. The grouping of strong and intermediate categories resulted also in not significant correlations (data not shown) (see Patients and Methods, and Results). $\mathrm{LRP}+$ represents the grouping of categories intermediate and strong; LRP- represents negative category. The grouping of intermediate and negative categories resulted also in not significant correlations (data not shown). For LRP grouping of categories intermediate and strong is shown due to the prognostic value on PFS and OS (see Patients and Methods, and Results).

\section{MDR status and response to induction chemotherapy}

Regardless of the grouping of the intermediate category, no significant association was observed between the expression of Pgp, MRP1, BCRP, and LRP and the response to induction chemotherapy (Table 4).

\section{MDR status and clinical outcome}

Three-year PFS for all 56 patients included in the survival analysis was $85.3 \%$ (95\% CI, 75.2-95.3\%), and 3-year OS 91.4\% (83.999.4\%). With seven relapses and four cancer-related deaths, median PFS and OS have not been reached. Regardless of the grouping of the intermediate category, no association was observed for Pgp, MRP1, and BCRP expressions either with PFS (strong $v s$ intermediate/negative: $P=0.307,0.284$, and 0.284 , respectively) or OS (strong $v s$ intermediate/negative: $P=0.932$, 0.98 , and 0.053 , respectively). For all three MDR proteins, the grouping of the strong plus intermediate category resulted in more unbalanced arms (very few patients in the negative category) and in lack of significant correlations (data not shown). In contrast, patients whose tumours showed intermediate or strong expressions of LRP had significantly shorter PFS $(P=0.0006$; Figure $2 \mathrm{~A})$ and OS $(P=0.0116$; Figure 3$)$ than LRP-negative patients. When considering the three original immunostaining categories separately, log-rank statistics for PFS and OS were $P=0.0008$ and 0.035 , respectively (Figure $2 \mathrm{~B}$ ). The grouping of the intermediate and strong categories discriminated better the outcome according to LRP expression. By univariate analysis, LRP was the strongest adverse prognostic marker for PFS $(P=0.0006)$ and OS $(P=0.0116)$, followed by $\beta$-hCG level $>5000 \mathrm{IU} \mathrm{l}^{-1}$ previous to induction chemotherapy ( $P=0.039$ for PFS, and $P=0.059$ for OS). Risk stratification according to the IGCCC (intermediate-poor $v s$ good) or RMH (stage IV $v s$ IM-II - III) did not achieve prognostic significance either for PFS ( $P=0.07$ and 0.481 , respectively) or OS ( $P=0.138$ and 0.38 , respectively) in this relatively small set of patients. As no recurrences or cancer-related deaths (i.e. events) were accounted among LRP-negative patients, no multivariate Cox regression analysis could be performed. Instead, we tested survival
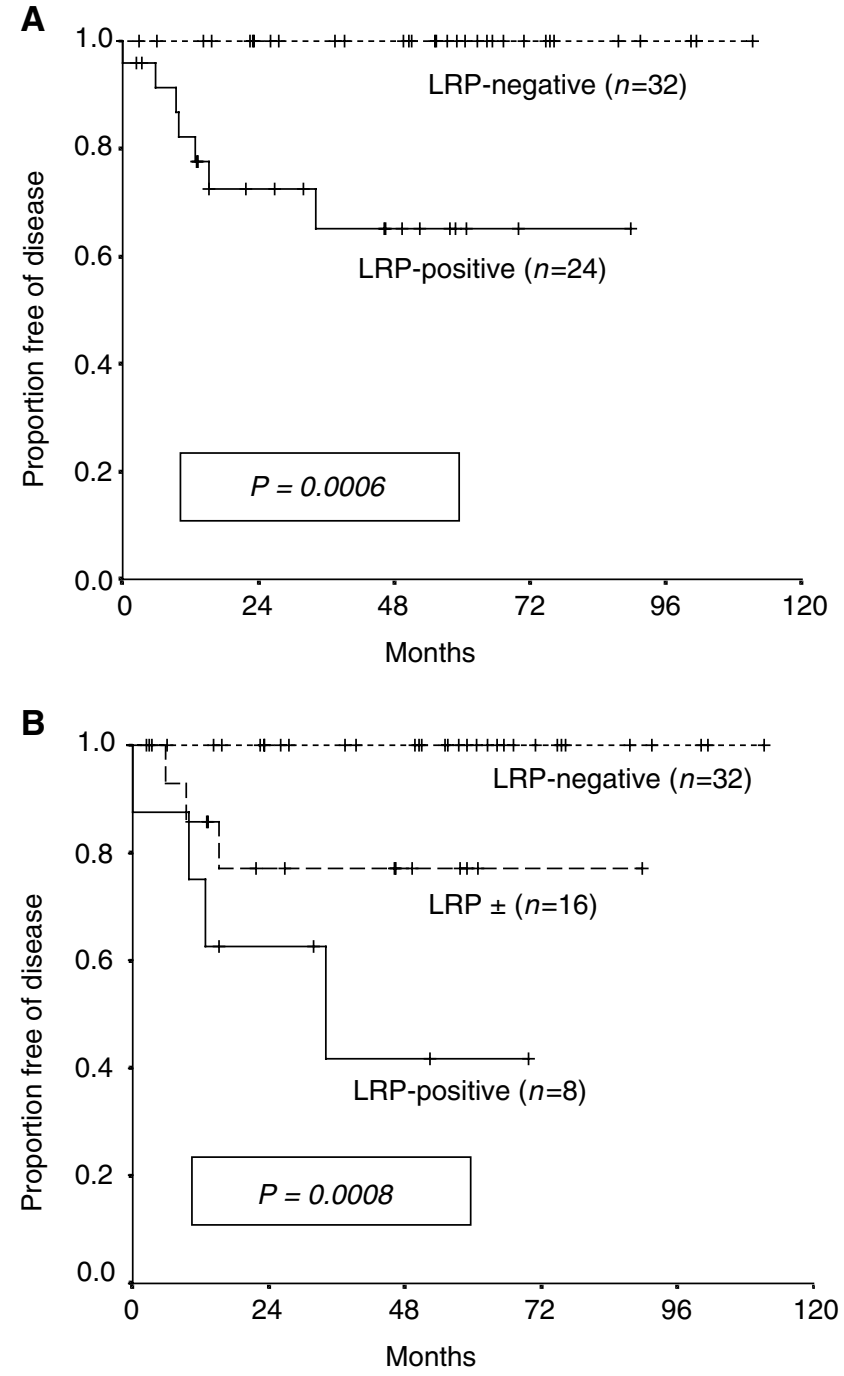

Figure 2 Progression-free survival according to LRP expression previous to treatment in 56 patients with advanced testicular germ-cell tumours. (A) Immunohistochemical categories strong and intermediate (grouped) vs negative. (B) Considering the three original immunostaining categories used for scoring (see Patients and Methods, and Results).

distributions for LRP adjusting for statistically related variables performing a stratified Mantel-Haenszel test. LRP remained significant after adjusting for $\beta$-hCG level $(P=0.0029$ for PFS, and $P=0.038$ for OS), and RMH stage $(P=0.001$ for PFS, and $P=0.02$ for OS).

\section{DISCUSSION}

The increasing need of new markers for prediction of response to chemotherapy and long-term PFS (the most relevant end point for TGCT patients in prognostic factor analyses), and the scarce data concerning the expression and significance of MDR-related proteins in TGCT, prompted us to initiate this study.

The most remarkable finding in our series of advanced TGCT was that LRP immunoreactivity in pretreatment tumour cells was prognostic of the clinical outcome. LRP immunostaining, at any level, was detected in $43 \%$ of the patients, consistent with the $50 \%$ previously reported in a short series with only 12 specimens (Izquierdo et al, 1996b). LRP is the human major protein of 


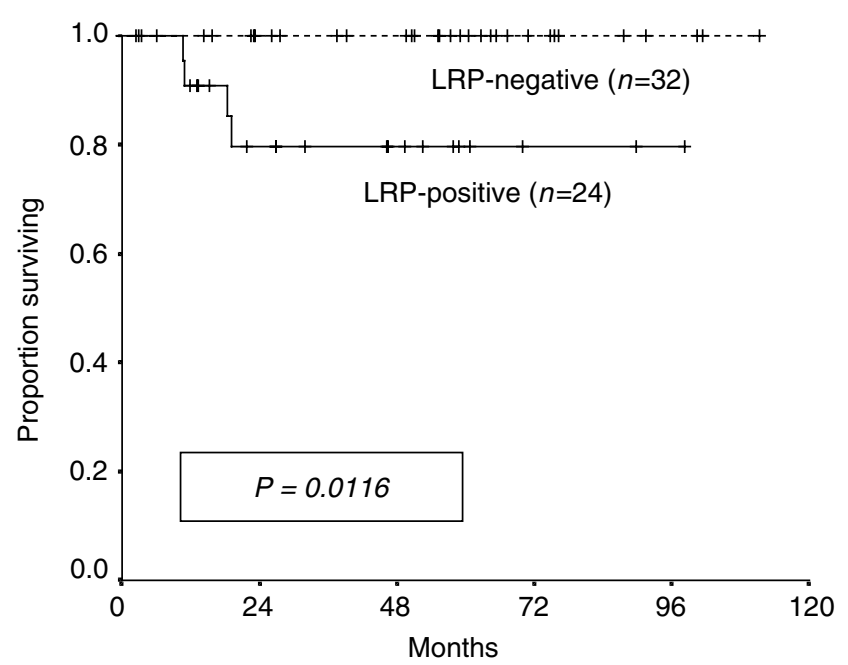

Figure 3 Overall survival according to LRP expression previous to treatment in 56 patients with advanced testicular germ-cell tumours. Immunohistochemical categories: strong and intermediate (grouped) vs negative.

cellular organelles known as vaults (Scheffer et al, 1995; for review, see Scheffer et al, 2000b), ribonucleoprotein particles with a peculiar ovoid structure that is highly conserved among various species. Vaults have been localised in the cytoplasm but also in the nuclear membrane, probably at the nuclear pore complex (Chugani et al, 1993). They have been found broadly distributed in normal human tissues and in tumours (Izquierdo et al, 1996b). Although vault function is yet undetermined, they are thought to mediate vesicular and nucleo-cytoplasmic trafficking and transport processes of various substrates including cytostatics (Chugani et al, 1993; Kitazono et al, 1999). The relevance of LRP as a constituent of the whole vault particle in the prediction of a MDR phenotype is well documented in vitro in numerous human cancer cell lines (Scheper et al, 1993; Izquierdo et al, 1996a; Laurençot et al, 1997; Kickhoefer et al, 1998). Kitazono et al (1999) recently provided the first evidence favouring a causal relation between vaults and drug resistance. Moreover, basal LRP expression has been found indicative for cisplatin and carboplatin resistance (nonclassical MDR-related drugs) in the NCI panel of 61 unselected human tumour cell lines used for drug screening (Izquierdo et al, 1996a), and in nonsmall-cell lung cancer cell lines (Berger et al, 2000).

In our study, any extent of LRP immunoreactivity including strong expression in a minority of cancer cells was associated with an unfavourable prognosis even after individual log-rank adjustments for statistically related prognostic factors. The strong biological and clinical rationale supporting the association of LRP with resistance to a broad spectrum of anticancer drugs, including cisplatin, and the fact that the two correlations found go in the same direction (LRP expression correlates with both shorter PFS and OS), makes unlikely that the positive analyses are due to multiple subset analysis. The frequent presentation of TGCT as mixed histologies and the potential significance for prognosis of a minor component in them make this a unique entity. Our finding adds to several clinical studies reporting overexpression of LRP at diagnosis as an independent predictor for clinical outcome and/or chemotherapy failure, for example, in acute myeloid leukaemia (List et al, 1996; Borg et al, 1998; Filipits et al, 1998, 2000), multiple myeloma (Raaijmakers et al, 1998; Filipits et al, 1999), stage III -IV ovarian carcinoma (Izquierdo et al, 1995), and locally advanced bladder cancer (Diestra et al, 2001). Other studies have failed to show prognostic values of LRP immunoreactivity in acute leukaemia (Damiani et al, 1998; Leith et al, 1999) and ovarian carcinoma (Arts et al, 1999). Despite the prognostic value of LRP in this study, no relation was observed between LRP expression and response to platinum-based chemotherapy. Whether this lack of correlation was because of the very high rate of CR observed (93\%, otherwise expected in TGCT) in our relatively small series of patients remains uncertain. As an alternative explanation, LRP may be a marker of biological aggressiveness in TGCT. This is suggested not only by the fact of poorer clinical outcomes for patients with LRP-expressing tumours, but also by the observed correlation between LRP and well-known factors conferring bad prognosis such as high $\beta$-hCG levels and visceral metastatic disease. Baldini et al (1995) found a similar conclusion for Pgp in high-grade osteosarcomas. They reported a strong correlation between the presence of increased levels of Pgp at diagnosis and bad prognosis that was unrelated to response to chemotherapy. We cannot exclude a potential influence of the histological subtype CC over the observed LRP value for prognosis in our series, as all of the CC elements stained for LRP (and $\beta$-hCG is elaborated by syncytiotrophoblastic components in CC). However, most prognostic classifications have failed to identify any particular histology as an independent variable for outcome (Mead et al, 1992). More detailed studies on the relation of LRP with clinicopathological parameters in TGCT are therefore warranted.

Pgp expression was observed in $27 \%$ of tumours, in agreement with previous reports (35\%, Katagiri et al, 1993; 33\%, Eid et al, 1998). In contrast to the report by Eid et al (1998), we found no association between Pgp expression and nonseminomatous histology or advanced stages of disease. This discrepancy can be attributed to our small number of seminomas and the use of different methodologies for Pgp detection. In agreement with the previous study, Pgp expression did not predict response to chemotherapy and was not related to survival. Neither in vitro nor clinical data suggest a relation between Pgp expression and resistance to cisplatin. However, the incorporation of etoposide, a substrate for Pgp (Germann, 1996), into combination chemotherapy regimens has improved response rates and long-term survival of poor-risk TGCT patients (Bosl and Motzer, 1997; Sonneveld et al, 2001). Whether the expression of Pgp in TGCT influences response to chemotherapy and outcome after regimens containing etoposide needs to be investigated in a much larger group of patients primarily treated with this drug.

There is only one previous study concerning MRP1 expression in TGCT (Eid et al, 2000). We report MRP1 overexpression in $54 \%$ TGCT, whereas Eid et al (2000) reported in 100\% using a different MAb but similar criteria for assessment. In our study, MRP1 expression did not predict response to chemotherapy or outcome. All attempts to demonstrate MRP1 as a mediator of cisplatin resistance have failed thus far; although MRP1 is involved in efflux conjugates of drugs to glutathione (one of the cellular thiol compounds involved in resistance to platinum agents; Borst et al, 2000). Eid et al (2000) reported MRP1 expression in the nucleus, in accordance with our observation, an intriguing binding of unclear significance. They speculated about a possible role for MRP1 unique to TGCT in the intracellular redistribution of drugs. However, we cannot exclude this finding being a staining artefact.

Recently, the novel ATP-dependent transporter BCRP was identified in mitoxantrone-selected MDR cell lines not expressing Pgp or MRP1 (Allikmets et al, 1998; Doyle et al, 1998). Thus far, BCRP has been described in cancer cell lines of different histogenetic origin (Scheffer et al, 2000a). Additionally, expression of BCRP has been reported in normal human tissues (Maliepaard et al, 2001), in a small panel of human tumour samples including two seminoma specimens (both considered BCRP-negative; Scheffer et al, 2000a), and in human breast carcinoma (Kanzaki et $a l, 2001$ ) and acute leukaemia (Ross et al, 2000). We report 
BCRP overexpression in $86 \%$ of TGCT, particularly in EC and in syncytiotrophoblasts in CC. The high expression rate of BCRP in placental syncytiotrophoblast (Maliepaard et al, 2001) is therefore retained in its malignant counterpart. BCRP did not predict response to chemotherapy and was not related to survival, consistent with its wide expression in TGCT and the limited role in this disease of the cytostatics to which BCRP confers resistance. In particular, BCRP is not involved in resistance to cisplatin (Allikmets et al, 1998; Doyle et al, 1998; Maliepaard et al, 1999).

In conclusion, our data suggest that the expression of LRP at the time of diagnosis of a metastatic TGCT may identify a patient population with a tendency to progress despite chemotherapy. The adverse prognostic value of LRP may be important because it may influence early selection of TGCT patients for novel therapeutic strategies. Moreover, the search for pharmacological agents capable of affecting vault function might also help in optimising treatment protocols in the future. However, because of the limited number of patients in this study, our results must be interpreted with caution. Whether LRP will increase the predictive power of current clinically oriented prognostic models remains to be determined in larger, prospective studies. The intriguing hypothesis derived from our study may prompt the initiation of such studies by institutions or collaborative groups capable of recruiting a large number of cases of this relatively rare type of cancer. We strongly encourage confirmation or rebuttal of our findings (especially the zero cell) by others.

\section{ACKNOWLEDGEMENTS}

We thank Dr Gabriel Capellà for support, and the personnel of the Laboratory of Translational Research, Institut Català d'Oncologia. This work was supported by the Spanish Fondo de Investigaciones Sanitarias (Grants FIS No. 98/0777 and 01/1560), and the Spanish Society of Medical Oncology (Grant SEOM '99 to Miguel A Izquierdo). This paper was presented in part at the 37th Annual Meeting of the American Society of Clinical Oncology, San Francisco, CA,USA in May 2001.

\section{REFERENCES}

Allikmets R, Schriml LM, Hutchinson A, Romano-Spica V, Dean M (1998) A human placenta-specific ATP-binding cassette gene (ABCP) on chromosome $4 \mathrm{q} 22$ that is involved in multidrug resistance. Cancer Res 58: $5337-5339$

Arts HJ, Katsaros D, de Vries EG, Massobrio M, Genta F, Danese S, Arisio R, Scheper RJ, Kool M, Scheffer GL, Willemse PH, van der Zee AG, Suurmeijer AJ (1999) Drug resistance-associated markers P-glycoprotein, multidrug resistance-associated protein 1, multidrug resistanceassociated protein 2, and lung resistance protein as prognostic factors in ovarian carcinoma. Clin Cancer Res 5: 2798-2805

Baldini N, Scotlandi K, Barbanti-Bròdano G, Manara MC, Maurici D, Bacci G, Bertoni F, Picci P, Scottili S, Campanacci M, Serra M (1995) Expression of P-glycoprotein in high-grade osteosarcomas in relation to clinical outcome. N Engl J Med 333: $1380-1385$

Berger W, Elbling L, Micksche M (2000) Expression of the major vault protein LRP in human non-small-cell lung cancer cells: activation by short-term exposure to antineoplastic drugs. Int J Cancer 88: $293-300$

Borg AG, Burgess R, Green LM, Scheper RJ, Yin JA (1998) Overexpression of lung-resistance protein and increased P-glycoprotein function in acute myeloid leukaemia cells predict a poor response to chemotherapy and reduced patient survival. $\mathrm{Br} J$ Haematol 103: $1083-1091$

Borst P, Evers R, Kool M, Wijnholds J (2000) A family of drug transporters: the multidrug resistance-associated proteins. J Natl Cancer Inst 92: $1295-1302$

Bosl GJ, Motzer RJ (1997) Testicular germ-cell cancer. $N$ Engl J Med 337: $242-253$

Chugani DC, Rome LH, Kedersha NL (1993) Evidence that vault ribonucleoprotein particles localize to the nuclear pore complex. J Cell Sci 106: $23-29$

Damiani D, Michieli M, Ermacora A, Candoni A, Raspadori D, Geromin A, Stocchi R, Grimaz S, Masolini P, Michelutti A, Scheper R, Baccarani M (1998) P-glycoprotein (Pgp), and not lung resistance-related protein (LRP), is a negative prognostic factor in secondary leukemias. Haematologia 83: 290-297

Diestra JE, García del Muro X, Zurita AJ, Condom E, Scheffer GL, MuñozSeguí J, Cardenal F, Pérez X, Scheper RJ, Germà-Lluch JR, Izquierdo MA (2001) Expression of MDR proteins LRP, BCRP, MRP1, and P-gp as predictors of response to neoadjuvant chemotherapy (NACT) and prognosis, in locally advanced bladder cancer (LABC). Proc Am Soc Clin Oncol 20: 73a (Abstract \#290)

Diestra JE, Scheffer GL, Català I, Maliepaard M, Schellens JHM, Scheper RJ, Germà-Lluch JR, Izquierdo MA (2002) Frequent expression of the multidrug resistance-associated protein BCRP/MXR/ABCP/ABCG2 in human tumours detected by the BXP- 21 monoclonal antibody in paraffin-embedded material. J Pathol 198: 213-219
Doyle LA, Yang WD, Abruzzo LV, Krogmann T, Gao Y, Rishi AK, Ross DD (1998) A multidrug resistance transporter from human MCF-7 breast cancer cells. Proc Natl Acad Sci USA 95: 15665-15670

Eid H, Géczi L, Mágori A, Bodrogi I, Institoris E, Bak M (1998) Drug resistance and sensitivity of germ cell testicular tumors: evaluation of clinical relevance of MDR1/Pgp, p53, and metallothionein (MT) proteins. Anticancer Res 18: 3059-3064

Eid H, Mingfang L, Institoris E, Bodrogi I, Bak M (2000) MRP expression of testicular cancers and its clinical relevance. Anticancer Res 20: 40194022

Filipits M, Pohl G, Stranzl T, Suchomel RW, Scheper RJ, Jager U, Geissler K, Lechner K, Pirker R (1998) Expression of the lung resistance protein predicts poor outcome in de novo acute myeloid leukemia. Blood 91: $1508-1513$

Filipits M, Drach J, Pohl G, Schuster J, Stranzl T, Ackermann J, Konigsberg R, Kaufmann H, Gisslinger H, Huber H, Ludwig H, Pirker R (1999) Expression of the lung resistance protein predicts poor outcome in patients with multiple myeloma. Clin Cancer Res 5: 2426-2430

Filipits M, Stranzl T, Pohl G, Heinzl H, Jager U, Geissler K, Fonatsch C, Haas OA, Lechner K, Pirker R (2000) Drug resistance factors in acute myeloid leukemia: a comparative analysis. Leukemia 14: $68-76$

Flens MJ, Izquierdo MA, Scheffer GL, Fritz JM, Meijer CJ, Scheper RJ, Zaman GJ (1994) Immunochemical detection of the multidrug resistance-associated protein MRP in human multidrug-resistant tumor cells by monoclonal antibodies. Cancer Res 54: 4557-4563

Flens MJ, Zaman GJR, van der Valk P, Izquierdo MA, Schroeijers AB, Scheffer GL, van der Groep P, de Haas M, Meijer CJ, Scheper RJ (1996) Tissue distribution of the multidrug resistance protein. Am J Pathol 148: $1237-1247$

Germà-Lluch JR, Begent RH, Bagshawe KD (1980) Tumour-marker levels and prognosis in malignant teratoma of the testis. Br J Cancer 42: 850 855

Germà-Lluch JR, García del Muro X, Tabernero JM, Sánchez M, Aparicio J, Alba E, Barnadas A (1999) BOMP-EPI intensive alternating chemotherapy for IGCCC poor-prognosis germ-cell tumors: the Spanish Germ-Cell Cancer Group experience. Ann Oncol 10: 289-293

Germann UA (1996) P-glycoprotein - a mediator of multidrug resistance in tumour cells. Eur J Cancer 32A: 927-944

Horwich A, Huddart R, Dearnaley D (1998) Markers and management of germ-cell tumours of the testes. Lancet 352: 1535-1538

Houldsworth J, Xiao H, Murty VVVS, Chen W, Ray B, Reuter VE, Bosl GJ, Chaganti RS (1998) Human male germ cell tumor resistance to cisplatin is linked to TP53 gene mutation. Oncogene 16: 2345-2349

International Germ Cell Cancer Collaborative Group (1997) International Germ Cell Consensus Classification: a prognostic factor-based staging system for metastatic germ cell cancers. J Clin Oncol 15: 594-603 
Izquierdo MA, van der Zee AGJ, Vermorken JB, van der Valk P, Belien JA, Giaccone G, Scheffer GL, Flens MJ, Pinedo HM, Kenemans P (1995) Drug resistance-associated marker LRP for prediction of response to chemotherapy and prognoses in advanced ovarian carcinoma. J Natl Cancer Inst 87: 1230 - 1237

Izquierdo MA, Shoemaker RH, Flens MJ, Scheffer GL, Wu L, Prather TR, Scheper RJ (1996a) Overlapping phenotypes of multidrug resistance among panels of human cancer cell lines. Int J Cancer 65: 230-237

Izquierdo MA, Scheffer GL, Flens MJ, Giaccone G, Broxterman HJ, Meijer CJ, van der Valk P, Scheper RJ (1996b) Broad distribution of the multidrug resistance-related vault lung resistance protein in normal human tissues and tumors. Am J Pathol 148: 877-887

Kanzaki A, Toi M, Nakayama K, Bando H, Mutoh M, Uchida T, Fukumoto M, Takebayashi Y (2001) Expression of multidrug resistancerelated transporters in human breast carcinoma. Jpn J Cancer Res 92: $452-458$

Kaplan EL, Meier P (1958) Nonparametric estimation from incomplete observations. J Am Stat Assoc 53: 457-481

Katagiri A, Tomita Y, Nishiyama T, Kimura M, Sato S (1993) Immunohistochemical detection of P-glycoprotein and GSTP1-1 in testis cancer. Br J Cancer 68: 125-129

Kersemaekers AMF, Mayer F, Molier M, van Weeren PC, Oosterhuis JW, Bokemeyer C, Looijenga LHJ (2002) Role of P53 and MDM2 in treatment response of human germ cell tumors. J Clin Oncol 20: 1551-1561

Kickhoefer VA, Rajavel KS, Scheffer GL, Dalton WS, Scheper RJ, Rome LH (1998) Vaults are up-regulated in multidrug-resistant cancer cell lines. J Biol Chem 237: 8971-8974

Kitazono M, Sumizawa T, Takebayashi Y, Chen ZS, Furukawa T, Nagayama S, Tani A, Takao S, Aikou T, Akiyama S (1999) Multidrug resistance and the lung resistance-related protein in human colon carcinoma SW-620 cells. J Natl Cancer Inst 91: 1647-1653

Laurençot CM, Scheffer GL, Scheper RJ, Shoemaker RH (1997) Increased LRP mRNA expression is associated with the MDR phenotype in intrinsically resistant human cancer cell lines. Int $\mathrm{J}$ Cancer $\mathbf{7 2}$ $1021-1026$

Lehnert M (1996) Clinical multidrug resistance in cancer: a multifactorial problem. Eur J Cancer 32A: $912-920$

Leith CP, Kopecky KJ, Chen IM, Eijdems L, Slovak ML, McConnell TS, Head DR, Weick J, Grever MR, Appelbaum FR, Willman CL (1999) Frequency and clinical significance of the expression of the multidrug resistance proteins MDR1/P-glycoprotein, MRP1, and LRP in acute myeloid leukemia. A Southwest Oncology Group Study. Blood 94: 10861099

List AF, Spier CS, Grogan TM, Johnson C, Roe DJ, Greer JP, Wolff SN, Broxterman HJ, Scheffer GL, Scheper RJ, Dalton WS (1996) Overexpression of the major vault transporter protein lung-resistance protein predicts treatment outcome in acute myeloid leukemia. Blood 87: $2464-$ 2469

Maliepaard M, van Gastelen MA, de Jong LA, Pluim D, van Waardenburg RC, Ruevekamp-Helmers MC, Floot BG, Schellens JH (1999) Overexpression of the BCRP/MXR/ABCP gene in a topotecan-selected ovarian tumor cell line. Cancer Res 59: 4559-4563

Maliepaard M, Scheffer GL, Faneyte IF, van Gastelen MA, Pijnenborg AC, Schinkel AH, van De Vijver MJ, Scheper RJ, Schellens JH (2001) Subcellular localization and distribution of the Breast Cancer Resistance Protein transporter in normal human tissues. Cancer Res 61: 3458-3464

Mantel N (1966) Evaluation of survival data and two new rank order statistics arising in its considerations. Cancer Chemother Rep 50: $163-170$
Mead GM, Stenning SP, Parkinson MC, Horwich A, Fossa SD, Wilkinson PM, Kaye SB, Newlands ES, Cook PA (1992) The Second Medical Research Council study of prognostic factors in nonseminomatous germ cell tumors. Medical Research Council Testicular Tumour Working Party. J Clin Oncol 10: 85-94

Mostofi FK, Sesterhenn IA (1998) Histological typing of testis tumours. In International Histological Classification of Tumours, 2nd ed, pp 7-17. Berlin, Heidelberg: Springer-Verlag.

Motzer RJ, Geller NL, Tan CC, Herr H, Morse M, Fair W, Sheinfeld J, Sogani P, Russo P, Bosl GJ (1991) Salvage chemotherapy for patients with germ cell tumors. The Memorial Sloan-Kettering Cancer Center experience (1979-1989). Cancer 67: 1305-1310

Peckham MJ, McElwain TJ, Barrett A, Hendry WF (1979) Combined management of malignant teratoma of the testis. Lancet 2: 267-270

Raaijmakers HGP, Izquierdo MA, Lokhorst HM, de Leeuw C, Belien JA, Bloem AC, Dekker AW, Scheper RJ, Sonneveld P (1998) Lung-resistancerelated protein expression is a negative predictive factor for response to conventional low but not to intensified dose alkylating chemotherapy in multiple myeloma. Blood 91: 1029-1036

Rao PH, Houldsworth J, Palanisamy N, Murty VVVS, Reuter VE, Motzer RJ, Bosl GJ, Chaganti RS (1998) Chromosomal amplification is associated with cisplatin resistance of human male germ cell tumors. Cancer Res 58: $4260-4263$

Ross DD, Karp JE, Chen TT, Doyle LA (2000) Expression of breast cancer resistance protein in blast cells from patients with acute leukemia. Blood 96: $365-368$

Scheffer GL, Wijngaard PL, Flens MJ, Izquierdo MA, Slovak ML, Pinedo HM, Meijer CJ, Clevers HC, Scheper RJ (1995) The drug resistancerelated protein LRP is the human major vault protein. Nat Med 1: $578-582$

Scheffer GL, Maliepaard M, Pijnenborg ACLM, van Gastelen MA, de Jong MC, Schroeijers AB, van der Kolk DM, Allen JD, Ross DD, van der Valk P, Dalton WS, Schellens JH, Scheper RJ (2000a) Breast cancer resistance protein is localized at the plasma membrane in mitoxantrone- and topotecan-resistant cell lines. Cancer Res 60: 2589-2593

Scheffer GL, Schroeijers AB, Izquierdo MA, Wiemer EA, Scheper RJ (2000b) Lung resistance-related protein/major vault protein and vaults in multidrug-resistant cancer. Curr Opin Oncol 12: 550-556

Scheper RJ, Bulte JW, Brakkee JG, Quak JJ, van der Schoot E, Balm AJ, Meijer CJ, Broxterman HJ, Kuiper CM, Lankelma J (1988) Monoclonal antibody JSB-1 detects a highly conserved epitope on the Pglycoprotein associated with multidrug-resistance. Int $J$ Cancer 42 389- 394

Scheper RJ, Broxterman HJ, Scheffer GL, Kaaijk P, Dalton WS van Heijningen TH, van Kalken CK, Slovak ML, de Vries EG, van der Valk P (1993) Overexpression of a M(r) 110,000 vesicular protein in non-P-glycoprotein-mediated multidrug resistance. Cancer Res 53: $1475-1479$

Sonneveld DJ, Hoekstra HJ, van der Graaf WT, Sluiter WJ, Mulder NH, Willemse PH, Koops HS, Sleijfer DT (2001) Improved long term survival of patients with metastatic nonseminomatous testicular germ cell carcinoma in relation to prognostic classification systems during the cisplatin era. Cancer 91: 1304-1315

Van Brussel JP, Mickisch GHJ (1998) Circumvention of multidrug resistance in genitourinary tumors. Int J Urol 5: 1-15

Van der Valk P, van Kalken CK, Ketelaars H, Broxterman HJ, Scheffer GL, Kuiper CM, Tsuruo T, Lankelma J, Meijer CJ, Pinedo HM (1990) Distribution of multi-drug resistance-associated P-glyco-protein in normal and neoplastic human tissues. Ann Oncol 1: 56-64 